International Journal of

BioScience and Applications

\title{
Analysis of Dietary Supplements intakes in Korean: Report Based on 2019 Korea National Health and Nutrition Examination Survey Data
}

\author{
Hae-Ryoung Park \\ Department of General Education, Kwangju Women's University, Republic of Korea
}

\begin{abstract}
$^{1}$
Background/Objectives: The purpose of this study was to analyze the overall pattern of dietary supplement intake as a method to maintain health. Based on the purpose of this study, it was intended to be used as basic data to establish the necessity of health functional food and the correct intake method. Methods/Statistical analysis: Statistical analysis method, Frequency analysis and chi-square test method was performed to analyze the data using IBM SPSS 21.0 program. Findings: When looking at whether or not they have taken dietary supplements continuously for more than 2 weeks in the past year, the number of women who answered 'yes' was high at $62.5 \%$ (2,462 people). Looking at the general matters of the survey subjects, '50-59' was $66.4 \%$, '6069' $63.5 \%$, and ' $40-49$ ' $63.2 \%$ in that order. Regardless of the level of learning, it was found that the experience of taking dietary supplements was high. By income level, 'low' 51.0\%, ' Low \& middle' 55.6\%, ' Middle \& high ' $59.4 \%$, and 'High' $65.3 \%$, indicating that the higher the income, the higher the experience of taking dietary supplements. Improvements/Applications: Based on this study, we intend to use it as a guideline for follow-up studies on the perception of nutritional knowledge and whether dietary supplements are consumed according to the guidelines of nutritional knowledge.
\end{abstract}

\section{Index Terms}

Balanced diet, Dietary supplement, Korea National Health and Nutrition Examination Survey, Healthy life, Nutritional knowledge

\footnotetext{
Corresponding author : Hae-Ryoung Park

hrpark@kwu.ac.kr

- Manuscript received April 15, 2021.

- Revised May 14, 2021 ; Accepted June 1, 2021.

- Date of publication June 30, 2021

(c) The Academic Society of Convergence Science Inc.

2619-8363 @ 2021 IJBSA. Personal use is permitted, but republication/redistribution requires IJBSA permission.
} 


\section{INTRODUCTION}

Nutrients and physiologically active substances for maintaining health and growth can be sufficiently ingested with a balanced diet, so it was common to recommend dietary supplements only for specific subjects. However, they have irregular eating habits due to their longer lifespan and daily life. As it was now, the number of age groups with restricted diets has increased due to the inability to engaged in various activities due to COVID-19. Although not included in conventional Western medicine for a long time, integrative medicine and health (IMH) and complementary and alternative medicine (CAM) have been used as healing approaches and therapies as medical therapy. The most commonly used integrative medicine and health and complementary and alternative medicine therapies were the use of dietary supplements, which include medicinal plants and nutraceuticals.

A recent study on total intake including dietary supplement intake showed that the nutritional intake status, contribution of dietary supplements, and lifestyle factors of children and adolescents and cancer survivors were analyzed in 2007-2009 and 2010-2011. It was reported through each national health and nutrition survey data. At this time, the experience rate of taking dietary supplements in Korea was around 30 40\% [1,2]. It was suggested that the proportion of people with insufficient intake decreased and the number of cases of excessive intake increased through dietary supplements, but only the average intake of the Koreans was presented, and no statistical analysis was performed, so no meaningful results were presented.

A large number of adults in the US population do not meet dietary guidelines due to insufficient intake of various nutrients. More than half of American adults say they didn't get enough dietary supplements [3]. Recent studies had shown that dietary supplements may help address nutritional deficiencies for immune support nutrients, as evidenced by the low prevalence in individuals with less than EAR [4].

A UK study found that people who took probiotics, omega-3 fatty acids, multivitamins, or vitamin D had lower rates of SARS-CoV-2 infection than those who didn't [5]. The study purpose was to provide basic data by statistical analysis of health functional food intake patterns as a way to maintain health. Using this study as basic data, it was intended to be used as statistical data to establish the necessity of health functional food and the correct intake method.

\section{RESEARCH METHOD}

In this study, the seventh Korea National Health and Nutrition Examination Survey (KNHANES VII-1) was a statutory survey conducted based on the Korea Disease Control and Prevention Agency statistics based on the Statistics Act. In compliance with the Personal Information Protection Act and the Statistics Act, the Korea Disease Control and Prevention Agency provides only de-identified data so that individuals cannot be estimated from the survey data. For this study, the raw data did not contain the contents that can confirm the subject's information, and the downloaded data was used only for this study and not for any other purpose other than this study.

\section{A. Research design}

This study was a secondary analysis using raw data from the 7th Korea National Health and Nutrition Examination Survey (KNHANES VII-1) conducted by the Korea Disease Control and Prevention Agency in 2019 to understand the actual situation of dietary supplement intake. A total of 7,184 subjects (male 3,206 and female 3942) were surveyed, and 7,148 of them were analyzed excluding missing values. 


\section{B. General Characteristics}

For general characteristics in this study, data on gender, age, education, and house income among health survey data from the seventh Korea National Health and Nutrition Examination Survey were used. Age was based on age, '20-29', '30-39', '40-49', '5059 ', '60-69', '70-79', and '>80'. Education level was classified into ' $<$ Middle school', 'middle school', 'high school', and ' $\geq$ University'. As for house income, household income was divided into 'low', 'lowermiddle', 'middle-high', and 'high' based on income quartiles.

To analyze the data on general characteristics, statistics were collected by the frequency analysis method. In order to examine the differences in dietary supplement intake by general characteristics, cross-analysis (chi-square test) used in the case of non-parametric method in categorical data was conducted to examine the differences between groups.

\section{Analysis Method}

The data were analyze the data using IBM SPSS 21.0 program. Frequency Analysis and chi-square test method was conducted. The significance level was set at $p<.01$.

\section{ReSUlts}

\section{A. General Characteristics}

The results regarding the general characteristics of the study subjects were as follows. The total number of participants is 8107 , and each item was the result of excluding missing values. Table 1 showed the results of the gender, age, education and house income of the subjects were expressed through frequency analysis.

Table 1. General characteristics $\quad(\mathrm{N}=7,148)$

\begin{tabular}{|c|c|c|c|}
\hline Characteristics & Categories & $\mathrm{N}$ & $\%$ \\
\hline gender & man & 3729 & 46.0 \\
\cline { 2 - 4 } & women & 4378 & 54.0 \\
\hline \multirow{4}{*}{ age } & $20-29$ & 749 & 9.2 \\
\cline { 2 - 4 } & $30-39$ & 985 & 12.1 \\
\cline { 2 - 4 } & $40-49$ & 1182 & 14.6 \\
\cline { 2 - 4 } & $50-59$ & 1245 & 15.4 \\
\cline { 2 - 4 } & $60-69$ & 1186 & 14.6 \\
\cline { 2 - 4 } & $70-79$ & 846 & 10.4 \\
\cline { 2 - 4 } & $>80$ & 349 & 4.3 \\
\hline Education & $<$ Middle school & 2273 & 28.0 \\
\cline { 2 - 4 } & Middle school & 755 & 9.3 \\
\cline { 2 - 4 } & High school & 2011 & 24.8 \\
\cline { 2 - 4 } & $\geq$ University & 2293 & 28.3 \\
\hline House income & Low & 1406 & 17.3 \\
\cline { 2 - 4 } & Low \& middle & 2163 & 26.7 \\
\hline
\end{tabular}

\begin{tabular}{|l|c|c|c|}
\hline & Middle \& high & 2143 & 26.4 \\
\cline { 2 - 4 } & High & 2355 & 29.0 \\
\hline
\end{tabular}

\section{B. Dietary Supplements Intake}

When looking at whether or not they have taken dietary supplements continuously for more than 2 weeks in the past year, the number of women who answered 'yes' was high at $62.5 \%$ (2,462 people) as shown in in Table 2.

Table 2. Whether you have taken dietary supplements for 2 weeks or more in the past year according to gender

\begin{tabular}{|l|l|c|c|c|c|}
\hline Characteristics & \multirow{2}{*}{ Categories } & \multicolumn{4}{|c|}{ Dietary Supplements } \\
\cline { 3 - 6 } & & \multicolumn{2}{|c|}{ Yes } & \multicolumn{2}{|c|}{ No } \\
\cline { 3 - 6 } & & $\mathrm{N}$ & $\%$ & $\mathrm{~N}$ & $\%$ \\
\hline gender & man & 1724 & 53.8 & 1,482 & 46.2 \\
\cline { 2 - 6 } & women & 2462 & 62.5 & 1480 & 37.5 \\
\hline Total & 4186 & 58.6 & 2962 & 41.4 \\
\hline$\chi 2(\mathrm{p})$ & \multicolumn{5}{|c|}{$54.911(.000) * * *$} \\
\hline
\end{tabular}

Looking at the general matters of the survey subjects, '50-59' was $66.4 \%$, '60-69' $63.5 \%$, and ' $40-49$ ' $63.2 \%$ in that order shown in in Table 3.

Table 3. Whether you have taken dietary supplements for 2 weeks or more in the past year according to age

\begin{tabular}{|c|c|c|c|c|c|}
\hline \multirow[t]{3}{*}{ Characteristics } & \multirow[t]{3}{*}{ Categories } & \multicolumn{4}{|c|}{ Dietary Supplements } \\
\hline & & \multicolumn{2}{|c|}{ Yes } & \multicolumn{2}{|c|}{ No } \\
\hline & & $\mathrm{N}$ & $\%$ & $\mathrm{~N}$ & $\%$ \\
\hline \multirow[t]{7}{*}{ Age } & $20-29$ & 272 & 43.9 & 347 & 56.1 \\
\hline & $30-39$ & 505 & 59.1 & 350 & 40.9 \\
\hline & $40-49$ & 655 & 63.2 & 381 & 36.8 \\
\hline & $50-59$ & 704 & 66.4 & 357 & 33.6 \\
\hline & $60-69$ & 664 & 63.5 & 382 & 36.5 \\
\hline & $70-79$ & 434 & 55.2 & 352 & 44.8 \\
\hline & $>80$ & 162 & 50.3 & 160 & 49.7 \\
\hline \multicolumn{2}{|l|}{ Total } & 3396 & 59.3 & 2329 & 40.7 \\
\hline \multicolumn{2}{|l|}{$\chi 2(\mathrm{p})$} & \multicolumn{4}{|c|}{$112.789(.000) * * *$} \\
\hline
\end{tabular}

By education level, $56.1 \%$ of ' $<$ Middle school', $57.6 \%$ of 'Middle school', $56.3 \%$ of 'High school', and $65.8 \%$ of ' $\geq$ University' were '<Middle school', and ' $\geq$ University'. Regardless of the level of learning, it was found that the experience of taking dietary supplements was high as shown in in Table 4.

Table 4. Whether you have taken dietary supplements for 2 weeks or more in the past year according to education 


\begin{tabular}{|l|c|c|c|c|c|}
\hline \multirow{3}{*}{ Characteristics } & \multirow{2}{*}{ Categories } & \multicolumn{4}{|c|}{ Dietary Supplements } \\
\cline { 3 - 6 } & & \multicolumn{2}{|c|}{ Yes } & \multicolumn{2}{|c|}{ No } \\
\cline { 3 - 6 } & $\mathrm{N}$ & $\%$ & $\mathrm{~N}$ & $\%$ \\
\hline Education & $\begin{array}{c}<\text { Middle } \\
\text { school }\end{array}$ & 1179 & 56.1 & 921 & 43.9 \\
\cline { 2 - 6 } & $\begin{array}{c}\text { Middle } \\
\text { school }\end{array}$ & 370 & 57.6 & 272 & 42.4 \\
\cline { 2 - 6 } & High school & 965 & 56.3 & 750 & 43.7 \\
\cline { 2 - 6 } & $\geq$ University & 1314 & 65.8 & 683 & 34.2 \\
\hline Total & 3828 & 59.3 & 2626 & 40.7 \\
\hline$\chi 2(\mathrm{p})$ & & \multicolumn{5}{|c|}{$50.893(.000) * * *$} \\
\hline
\end{tabular}

By income level, 'low' 51.0\%, 'Low \& middle' 55.6\%, ' Middle \& high ' $59.4 \%$, and 'High' $65.3 \%$, indicating that the higher the income, the higher the experience of taking dietary supplements as shown in Table 5.

Table 5. Whether you have taken dietary supplements for 2 weeks or more in the past year according to house income

\begin{tabular}{|c|c|c|c|c|c|}
\hline \multirow{3}{*}{ Characteristics } & \multirow[t]{3}{*}{ Categories } & \multicolumn{4}{|c|}{ Dietary Supplements } \\
\hline & & \multicolumn{2}{|c|}{ Yes } & \multicolumn{2}{|c|}{ No } \\
\hline & & $\mathrm{N}$ & $\%$ & $\mathrm{~N}$ & $\%$ \\
\hline \multirow[t]{4}{*}{ House income } & Low & 635 & 51.0 & 610 & 49.0 \\
\hline & $\begin{array}{l}\text { Low \& } \\
\text { middle }\end{array}$ & 1070 & 55.6 & 854 & 44.4 \\
\hline & $\begin{array}{c}\text { Middle \& } \\
\text { high }\end{array}$ & 1133 & 59.4 & 775 & 40.6 \\
\hline & High & 1334 & 65.3 & 710 & 34.7 \\
\hline \multicolumn{2}{|l|}{ Total } & 4172 & 58.6 & 2949 & 41.4 \\
\hline \multicolumn{2}{|l|}{$\chi 2(p)$} & \multicolumn{4}{|c|}{$74,575(<.001) * * *$} \\
\hline
\end{tabular}

\section{CONCLUSION AND Discussion}

When asked if they had taken health functional food for 2 weeks or more within the past year, $62.5 \%$ of women answered 'yes'. Women showed higher interest than men. By age, '50-59' had the highest consumption experience, followed by '60-69' and '40-49'. Even in those over 80 years of age, $50.3 \%$ of them experienced ingestion, which was higher than that of ' $20-29$ ' (43.9\%).

As a result of examining health functional food intake and nutritional status of the elderly according to gender for men and women over 65 years of age, it was thought that women consume health functional food as a preventive measure to maintain their health. It was assumed that men consume health functional food as an auxiliary means of treatment to recover their health, so there was a difference in viewpoints according to gender [6]. As a way to maintain health, it was necessary to practice lifestyle improvement methods related to eating habits and exercise. In addition to these methods for leading a healthy life, dietary supplement intake was emerging as a new lifestyle management method. As in the results of this study, it can be seen that the intake of dietary supplements increases with age. Also, it was found that the degree of education was not significantly affected. Based on this study in the future, we intend to use it as a guideline for follow-up studies on whether dietary supplements are consumed according to the awareness of nutritional knowledge or the guidelines of nutritional knowledge.

\section{REFERENCES (APA STYLE)}

[1] Kang M, Kim DW, Lee H, Lee YJ, Jung HJ, Paik HY et al. The nutrition contribution of dietary supplements on total nutrient intake in children and adolescents. Eur J Clin Nutr. 2015; 70(2):257-261.

[2] Song S, Youn J, Lee YJ, Kang M, Hyun T, Song $\mathrm{Y}$ et al. Dietary supplement use among cancer survivors and the generalpopulation: a nation-wide cross-sectional study. BMC cancer. 2017;17(1):891902.

[3] Ruopeng An, Chung-Yi Chiu, Flavia Andrade. Nutrient intake and use of dietary supplements among US adults with disabilities. Disabil Health J. 2015;8(2):240-9.

[4] Carroll A Reider, Ray-Yuan Chung, Prasad P Devarshi, Ryan W Grant, Susan Hazels Mitmesser. Inadequacy of Immune Health Nutrients: Intakes in US Adults, the 2005-2016 NHANES. Nutrients. 2020;12(6): 1735 .

[5] Panayiotis Louca,Benjamin Murray, Kerstin Klaser, Mark S Graham, Mohsen Mazidi, et al. Modest effects of dietary supplements during the COVID-19 pandemic: insights from 445850 users of the COVID-19 Symptom Study app. BMJ Nutrition, Prevention \& Health. 2021;1-9.

[6] Gham Minju, Um Mihyang, Kye Seunghee. Evaluation of Dietary Quality and Nutritional Status based on Nutrition Quotient and Health Functional Food Intake in the Korea Elderly. J. Korean Soc. Food Cult. 2019;34(4):474-485. 